\title{
Re-Imagining the First Year as Catalyst for First-Year Writing Program Curricular Change
}

\author{
Virginia Crank \\ University of Wisconsin-La Crosse \\ vcrank@uwlax.edu \\ Sara Heaser \\ University of Wisconsin-La Crosse \\ sheaser@uwlax.edu \\ Darci L. Thoune \\ University of Wisconsin-La Crosse \\ dthoune@uwlax.edu
}

\begin{abstract}
This article describes a revision of a first-year writing program curriculum using the pillars of the Reimagining the First-Year Program. The authors adapted principles related to mindset and habits of mind from both college retention scholarship and composition scholarship. After developing a research project in order to understand what elements of mindset correlate with readiness for creditbearing writing courses, the authors created a multiple measures placement system for enrolling students in a credit-bearing first-year writing course with co-requisite support.
\end{abstract}

Keywords: Re-imagining the first year (RFY), first-year writing, multiple measures placement, corequisite course, retention, habits of mind, remedial education, mainstreaming, basic writing

National conversations about higher education regularly return to questions about student persistence, particularly in response to reports like the one circulated by the National Student Clearinghouse Research Center. Their 2014 data shows that only 68.7\% of first-time students in 2012 returned to any institution of higher education in 2013. The response to some of these trends has been to explore why students leave, what characteristics mark the students who stay, and how to develop programs which enact that knowledge. This response turns more toward behavioral and attitudinal qualities than academic qualifications or benchmarks, with the mindset psychological work by Stanford professor Carol Dweck (2006) and the "sense of belonging" research by Terrell Strayhorn (2012) taking a central position in these conversations.

At the disciplinary level, the question of what characteristics mark successful students has been explored by those who teach secondary and postsecondary English, resulting in the 2011 report $A$ Framework for Success in Postsecondary Writing, co-produced by the National Council of Teachers of English, the Council of Writing Program Administrators, and the National Writing Project (2011). This document, like the retention research, focuses not on discrete skills or academic credentials as markers of potential for success but on "Habits of Mind," echoing the trend in college retention and persistence circles to focus on mindset and the sense of belonging as keys to promoting student success.

This article takes up the two threads above (college retention and success in college writing) in the specific context of a first-year writing program (FYW). We have turned the question of retention to an examination of the transition to college writing for those students who have traditionally been placed in non-credit-bearing writing courses (also known as "basic," "remedial" or "developmental" 
writing; for this article, we'll use basic writing or BW ${ }^{1}$ ). It is our attempt to make assessment-specifically assessment for placement into first-year writing courses--local, humane, organic, and context-sensitive as called for by assessment scholars like Brian Huot (2002) and Bob Broad (2003). Seeking to better serve first-year students who come to us in need of additional academic support, we tapped into a university-level retention program that offered an avenue toward more ethical placement practices.

\section{Background}

The University of Wisconsin-La Crosse (UWL) is a four-year comprehensive institution which serves around 10,500 students (9,000+ undergrad); UWL occupies a somewhat privileged position in the UW System, as it maintains high admissions standards (second only to the anchor campus at Madison) and is consistently ranked highly by US News and World Report's America's Best Colleges list; in 2018, it was ranked as the number one comprehensive campus in the UW System and in the top four among regional universities in the Midwest. Our students tend to be high achievers; the average ACT of the incoming student is 24.7 , and $25 \%$ of these students were in the top $10 \%$ of their graduating high school class. A small number of new students each year are placed into remedial courses in English and Mathematics based primarily on scores on standardized placement tests. These tests, developed in the 1970s, are written by committees of faculty from every UW school and are overseen by the UW Center for Placement Testing which does regular validity and reliability testing. Some UW institutions use the English Placement Test (EPT) score in conjunction with other placement measures to place students in first-year writing courses. At UWL, the score has been used to place students into one of two courses: the sole credit-bearing gateway first-year writing requirement, ENG 110, or the remedial non-credit-bearing ENG 050, which students must complete before taking ENG 110. Only 1.4\% of incoming students score below 355, the cut-off for the credit-bearing gateway course (the average EPT score of an incoming student is 495), and the average ACT of "remedial" UWL students is 21. The average number of students scoring below the 355 cut-off for the whole UW System is $6 \%$, so UWL serves far fewer underprepared students than other UW schools, and even those students who might be categorized as remedial here have academic performance markers that would qualify them for credit-bearing English courses at many institutions. Because of these statistics and the growing move in composition pedagogy to eliminate non-credit-bearing remedial courses, we have been working on a proposal to mainstream all students into ENG 110 and create a co-requisite support course for students who might have previously been placed in ENG 050. This proposal coincided with our university's participation in a program focused on improving student success in the first year of college.

UWL is a member institution in the American Association of State Colleges and Universities (AASCU) and has participated in AASCU's program "Re-imagining the First Year" (RFY), which is a grant-supported national project targeting "low income, first generation, and students of color," for whom the first year of college can make a significant difference in their retention and success (2016). Their website explains, "AASCU has created a coalition of 44 member institutions that are working together for three calendar years (2016-2018) to develop comprehensive, institutional transformation that redesigns the first year of college and creates sustainable change for student success." The RFY member institutions work on four "pillars" to increase retention: institutional intentionality,

\footnotetext{
${ }^{1}$ While many academic disciplines refer to the student population needing additional coursework before college-level work as "remedial" or "developmental," the field of composition studies prefers to refer to these students as "basic writers" and the courses they take as "basic writing."
}

Journal of the Scholarship of Teaching and Learning, Vol. 19, No. 1, February 2019. josotl.indiana.edu 
curriculum, faculty and staff, and student success. At UWL, this program is being used in part to redesign a one-credit first-year experience (FYE) course, UWL 100. While there are many models for FYE courses, UWL 100 had been an "introduction to college" type course designed to engage students in conversations about making the transition from high school to college and understanding the basic structures and modes of college courses. Through RFY, this course has been restructured to include a focus on engagement, belonging, and growth mindset and has changed from an optional course for all students to a required course for students who come from groups with a history of academic underpreparedness. These required FYE courses are now linked to particular student populations and/or general education courses. This course has been UWL's RFY focus because although UWL has an $83 \%$ retention rate for first-year students, first-generation college students, students from underrepresented racial/ethnic groups, and students from low-income families don't achieve at that high of a rate (generally $4-5 \%$ below the average).

These same groups of students, along with returning and transfer students, veterans, and international students, are more likely to be overrepresented in basic writing courses, and research suggests that retention rates for these students are negatively affected by remedial courses. The university's participation in RFY coincided with our plans for changing our BW program and offered us the opportunity to pilot the mainstreaming of a small number of students into the credit-bearing FYW course, using the revised UWL 100 as our co-requisite support course. Both the common cohort of students -- first-generation students, low-income students, and students of color -- and the common goal of retention beyond the first year made the partnership between these programs ideal. This article will describe that partnership and how the pilot co-requisite courses led to revision of the BW program and the creation of a new placement protocol and co-requisite support course in English.

\section{Literature Review}

Scholarship relating to this research project comes from several fields: student success and retention, particularly related to remedial education; first-year writing program revisions and best practice; and multiple-measures placement. The intersections of these research areas provide critical lenses for supporting the revision of the basic writing program at UWL.

Research from Complete College America (CCA) indicates that over one million college students annually are placed in remedial courses and that few of these students (only 36\%, for 4-year institutions) go on to complete the gateway course that the remediation is meant to prepare them for. The research also notes that low-income students and students of color are disproportionately represented in remedial courses, leading to much lower retention rates for these students. CCA proposes that the solution to this remediation and retention problem is providing co-requisite remediation alongside credit-bearing college courses. Several states have implemented this solution and have demonstrated a marked improvement in successful completion of gateway courses with corequisite remediation programs. This research provides significant motivation to consider how to move more students out of non-credit-bearing remedial courses and position them for success in firstyear courses.

In gateway courses such as mathematics, the movement into credit-bearing courses and corequisite support can happen with fairly simple adjustments in standardized test scores. However, for FYW the issue of placement is a bit more complicated. Beth Brunk-Chavez and Elaine Frederickson (2008) remind us that "Placement scores, regardless of how they are generated, are generally meant to indicate that a student will be capable of succeeding in the appropriate course (p. 80). So, how do we best use placement scores to put students in the appropriate kind/level of writing class? Can we use "a one size fits all" approach to placement (like with standardized testing) that is both accurate and ethical? The answer seems to be, no; Holly Hassel and Joanne Baird Giordano (2011) discuss the

Journal of the Scholarship of Teaching and Learning, Vol. 19, No. 1, February 2019. josotl.indiana.edu 
importance of moving from a standardized exam to a multiple measures placement (MMP) system for their FYW students, arguing that, "As a stand-alone placement measure, a standardized test can evaluate only a small part of what students need to be able to do as college readers and writers" (30). Additionally, standardized tests are often "decontextualized from the writing experiences students will have in their coursework" and are "typically designed to measure performance, not potential" (BrunkChavez and Frederickson 2008).

Brunk-Chavez and Frederickson (2008) suggest that placement should occur in a more local context, noting that assessors can judge the potential in a student's placement performance best through a multiple measures system. They echo Rich Haswell (2004) who says, "Educators who wish to measure writing promise, through whatever the system of placement, should implement multiple measures and validate with multiple measures." Hassel and Giordano (2011) also emphasize the importance of a locally-situated placement process that aligns with a FYW programs' outcomes, describing a "flexible and local" process that gives more agency and validation to students and the knowledge they bring to the institution. Hassel and Giordano, and their colleagues at the UW Colleges, integrated an essay and self-assessment component into their placement measures, enabling them to create a tool that more accurately captures their local first-year student population.

Any placement system that accounts for location, context, and the particular nature of FYW programs is better positioned to work for student success (i.e. retention) because research shows that FYW is uniquely positioned to improve retention. Garrett, Bridgewater, and Feinstein (2017) look specifically at the role FYW plays in predicting a students' success at college, finding that performance in "writing courses strongly predicts both graduation and success in the major" (p. 107). Because of its smaller class size, content, and emphasis on metacognition, among other things, FYW becomes one of several potential points of intervention for first-year students.

However, Pegeen Reichert Powell (2009) presents a somewhat contradictory assertion about the role of FYW in retention, contending that FYW courses may play only a small part. She seems more interested in encouraging composition professionals to examine what happens to students before they get to FYW -- what practices and cultures make it possible for them to even get into that class -- because if we want FYW to play a role in retention, we've got to look at placement. She also urges us to consider what the course might look like "if it is formulated in the context of retention scholarship, keeping in mind those students in our first-year courses who may not persist" (p. 678).

One response to Powell's call for deliberate use of retention scholarship to guide FYW pedagogical practices is the National Council of Teachers of English's (NCTE) Research Policy Brief, "FYW, What Good Does It Do?" (2013) which describes specific ways FYW fosters engagement and retention, enhances rhetorical knowledge, develops metacognition, and increases responsibility. According to the brief, "Research suggests that FYW is uniquely placed in the undergraduate curriculum to develop student metacognitive awareness, the development of which has the potential to have resounding consequences on student postsecondary education and writing (p. 2)." Two other key factors in college retention that are also provided by FYW courses are personal attention and low student/teacher ratios. These characteristics explain why FYW courses are "formative moments for students' life-long learning and writing experiences" that encourage student retention and persistence.

Research from this policy brief combined with the research of Carol Dweck on mindset and research on habits of mind from NCTE et al. provide solid evidence that the influence of FYW on student retention, success, and persistence cannot be overstated. This connection positions our project as an ideal partner for an RFY initiative that seeks to understand the importance of the first year of college.

Journal of the Scholarship of Teaching and Learning, Vol. 19, No. 1, February 2019. josotl.indiana.edu 


\section{Research Questions and Methodology}

Based on the literature above, using a one-size-fits-all placement method and placing students into non-credit bearing remedial courses does not help colleges and universities meet the writing and learning needs of their students. This understanding made eliminating ENG 050 on our campus a logical move. However, we did not have much student voice involved in a program revision that directly affected them; we did not know much about the specific kinds of knowledge or awareness these students were bringing to our campus. If we wished to move to a locally-constructed and flexible MMP system, we needed more context about our students. The EPT, while largely an accurate placement tool for most students on campus, did not provide some crucial information about our students: their experiences with and perceptions about writing.

We initially hypothesized in the 2015-16 AY, based on EPT scores only, that although ENG 050 may no longer be necessary, there would still be a population of students who could benefit from supplemental writing instruction alongside our FYW course. We informally named this pocket of students "cuspy." We had a sense of what cuspy looked like based on informal interactions with and observations of first-year students. In some cases students were cuspy because of a lack of confidence; in others, a lack of awareness of audience and sometimes a string of bad writing experiences affected their abilities to be flexible or persistent. Because we wished to explore these hypotheses on a more formal basis, our curriculum revision organically evolved into a research project. Over the course of one academic year, we gathered data about first-year writing students, including: ACT scores, EPT scores, in-class writing samples, surveys, and coursework to help us define cuspy on our campus. The larger research questions that drove our data collection were:

- Do we need a basic writing class on a campus with such high admission standards?

- If we don't have a basic writing program, how can we still assist students who need additional support?

- Are there particular characteristics in student writing that suggest unpreparedness for college writing? Are there particular habits of mind that suggest unpreparedness for college writing?

- What placement tools could offer a glimpse into this unpreparedness? How should we design those tools?

- How do students' perceptions of themselves as writers feed into our definition of cuspy?

After receiving IRB approval from our University, we gathered data during the 2015-16 AY from a total of 140 students, 30 of which were in ENG 050 and the remainder from ENG 110. For each student, we collected the following:

- EPT scores;

- ACT composite and English sub-scores;

- Responses to a forty-question survey distributed during the first week of classes;

- Two in-class writing responses ${ }^{2}$, one that called for students to reflect on the Framework for Student Success in Postsecondary Education: Habits of Mind, and another that called on them to write a revision plan for that in-class writing, both completed during the first week of classes;

- ENG 050 or ENG 110 coursework, which included final, polished essays submitted via a portfolio at the end of the semester.

\footnotetext{
${ }^{2}$ These response prompts were adapted from Holly Hassel and Joanne Giordano's MMP materials used by the UW Colleges.
} 
Because 355 is the cutoff EPT score, we focused on the 320-420 EPT score range, particularly the range of 350-370, which we considered a cuspy range. Students who scored 350 or below would have been placed into ENG 050; and those who scored 380 and above were academically prepared. We collaboratively read each student's coursework alongside their two in-class "Habits of Mind" responses to explore:

- The reliability of the EPT score to confirm our assumption that it is an accurate placement tool and predictor of academic ability;

- General patterns in students' "Habits of Mind" responses or coursework that revealed inconsistencies in our hypotheses;

- Possible correlations between various data points: EPT scores and "Habits of Mind" responses; EPT scores and quality of coursework; or quality of coursework and quality of "Habits of Mind" response.

We came to the following realizations that encouraged us to re-evaluate our research questions and placement practices:

1. Students who scored higher on the EPT did have stronger coursework and "Habits of Mind" responses in general. Students even at the low end of our targeted EPT score range (350-370) were prepared for FYW; as a result, there was no reason to look at students with a score higher than 350. Therefore, we made the cuspy "window" lower and smaller: 330-350;

2. Unpreparedness can be defined in many different ways. When reading student writing from those who scored 350 or below, we identified a wide variety of characteristics that signaled to us that these students might not be ready for FYW;

3. Coursework that has been revised is not a reliable piece of data to look at for placement. The "Habits of Mind" responses and survey results offer a more accurate and authentic picture of a beginning college writer;

4. Crafting a multiple measures placement tool will be more difficult than expected; how should we design it, if we can't discern consistent markers of unpreparedness in the first place?

While we were analyzing the data in June 2016, a colleague of ours who was invested in the RFY project on our campus offered us the opportunity to teach a Fall 2016 section of UWL 100, our one-credit First-Year Seminar, which would be linked to a section of ENG 110; students would enroll in both courses simultaneously. The purpose of these linked courses was to foster a sense of belonging and community in first-year students who are more prone to feeling isolated in a new environment. We enthusiastically agreed and linked one UWL 100 section to a small cohort of ENG 110 sections-each section had a few students who had scored either a 340 or 350 on the EPT and should have been enrolled in ENG 050 but would now instead be mainstreamed into ENG 110. We called these our "Golden Ticket" students (a la Willy Wonka) because during freshman registration these students literally received yellow pieces of paper in their registration materials indicating that they had been chosen to participate in this pilot project. While we didn't yet have specific data-driven research results to support this move, our expertise and experience teaching both the remedial and FYW courses and our initial collaborative reading were enough for us to cautiously proceed with this experiment.

During this co-requisite pilot semester, we returned to our survey results from the 2015-16 AY because an initial research question remained unanswered: "Are there particular writing characteristics or habits of mind that might suggest unpreparedness for college writing?" To examine this question, we analyzed the survey responses, which included more specific, direct questions and opportunities for students to assess themselves as writers.

Journal of the Scholarship of Teaching and Learning, Vol. 19, No. 1, February 2019. josotl.indiana.edu 
The survey divided forty questions, adapted from the National Survey on Student Engagement (NSSE) and the Daly-Miller Apprehension Test, into four categories: Apprehension, Genre Exposure, Writing Perceptions and Habits, and Writing Practices and Prior Instruction. Students responded on a five-point Likert scale. Examples of categories and response statements appear in Table 1.

Table 1: Example of Survey Categories and Statements

\begin{tabular}{|l|l|l|l|l|}
\hline & Apprehension & Genre Exposure & $\begin{array}{l}\text { Writing } \\
\text { Perceptions and } \\
\text { Habits }\end{array}$ & $\begin{array}{l}\text { Writing } \\
\text { Practices and } \\
\text { Prior } \\
\text { Instruction }\end{array}$ \\
\hline $\begin{array}{l}\text { Statement } \\
\text { Example }\end{array}$ & I avoid writing. & $\begin{array}{l}\text { In High School, I } \\
\text { summarized a I write, my } \\
\text { piece that I read. }\end{array}$ & $\begin{array}{l}\text { As High School, I } \\
\text { ideas about my } \\
\text { subject change. }\end{array}$ & $\begin{array}{l}\text { Instructor about } \\
\text { talked with an } \\
\text { my witing before } \\
\text { submitting it for a } \\
\text { grade. }\end{array}$ \\
\hline Likert Scale & $\begin{array}{l}\text { Strong Disagree } \\
\text { (1) to Strongly } \\
\text { Agree (5) }\end{array}$ & $\begin{array}{l}\text { All Assignments } \\
\text { to No }\end{array}$ & $\begin{array}{l}\text { Never (1) to } \\
\text { Always (5) }\end{array}$ & $\begin{array}{l}\text { All Assignments } \\
\text { (1) to No } \\
\text { Assignments (5) }\end{array}$ \\
\hline
\end{tabular}

To analyze the survey results, we first identified overall trends in responses. Then, we divided survey responses into four quartiles based on EPT score in order to determine if there were correlations between these quartiles and the average response in each category. We were particularly interested in setting up this correlation because of the 340-350 score range used for placement into UWL 100. We looked for patterns across quartiles, such as:

- Does a particular EPT score quartile correlate with any overall category of response?

- More specifically, do students with a lower EPT score have higher levels of writing apprehension?

- Do students with a higher EPT score have more previous experience writing in a variety of genres? And in various stages of the writing process?

- Do EPT scores correlate with student perceptions of writing ability?

For nearly every question in all categories, the average response for all cohorts across all test score quartiles was 3, right in the middle of the Likert scale, which reflected the objective choices "neutral" or "occasionally," depending on the statement's context. More specifically, the average for Apprehension was 2.9; for Genre Exposure, 3.1; for Writing Perceptions and Habits, 3.4; for Writing Practices and Prior Instruction, 2.8. While these questions asked students to consider very different contexts about their writing, the results instead reflected synonymous experiences, contradictory experiences, or a sense of indifference. For example, we were puzzled by students who responded "agree" to "I avoid writing" while simultaneously marking "disagree" for "When I revise, I mostly look at grammatical and mechanical errors." This suggests the student avoids writing, but at the same time, understands and perhaps values thorough revision. Results were particularly contradictory in the Genre Exposure section, as some students marked "some assignments" for nearly every genre listed, 
which seems, based on our experience, an inaccurate representation of a typical high school curriculum from our cohort.

Because of these confusing results, we compared responses across more specific cohorts. In comparing rankings from students enrolled in ENG 050 to those enrolled in ENG 110, no statistically significant differences were found. Responses were so similar for both cohorts, in fact, that the standard deviation was a surprisingly low .3 for the entire survey. In comparing responses from the top quartile to the lowest, no statistically significant differences were found in any of the four categories. The data's p-value was calculated for reliability testing, which affirmed these results were accurate. These results reinforced the hypothesis that basic writers were not a discernible population on our campus.

But when we interpreted this same data through a different lens--that of RFY--it told a very different story.

As mentioned previously, one of the four core pillars of RFY is student success, which challenges participating institutions to "consider the student experience on campus, particularly focusing on engagement, belonging, and growth mindset" (Arney, Canada, Dale 2018). After being introduced to RFY principles on campus, which also happened to be after the survey was administered and analyzed, we realized many of the questions mapped above in table 1.2 assess a student's mindset towards writing, like "I avoid writing" or "I write effectively without much drafting and revising." Others reflect a student's engagement with their academic work, like "I analyze and evaluate my own writing" or "I use feedback from others to improve my own writing." Instead of looking for differences within cohorts to define cuspy, we shifted to a more holistic reading to gauge the level of academic preparedness of first-year writers on our campus. One of the many results of this holistic reading was the development of an MMP rubric that evaluates the following: student's ability to work through and follow a prompt, the student's ability to synthesize sources and ideas at a beginning level, and the student's ability to reflect on their writing choices.

Through this lens, these students seemed unable to assess their own academic preparedness, which supports the idea that they have underdeveloped metacognition, an essential skill for success in postsecondary education, and one listed as a key facet in the Framework discussed earlier.

With new interpretations and the supportive context of RFY, we realized that best practices in academic preparedness and FYE were underutilized and less explicit than they should be in FYW. Re-envisioning this survey allowed us to reevaluate our linked courses and our FYW program; both are important points of intervention for at-risk and underprepared students on our campus.

In fall 2017 we ran another pilot "Golden Ticket" section of UWL 100 again and utilized these realizations to revise the course, focusing on the explicit inclusion of FYE principles. We co-taught the course and hired two in-class student mentors so students had more small group and one-on-one interaction in the classroom; we set the curriculum to focus on writing practices that engage habits of mind, such as collaborative, low-stakes, and reflective writing, revision, and portfolios; and we included readings and framed in-class discussions around mindset, among other things. We hoped these changes would help students became more aware of themselves as writers, as college students, and as people participating in a larger university community to which they belong. This awareness, though foundational, is essential to developing a confident identity as a writer.

\section{Implementation and Implications}

Using the above research and collaboration with the RFY initiative and findings from our two pilot sections of UWL 100, we revised the basic writing component of our FYW program with the following changes:

Journal of the Scholarship of Teaching and Learning, Vol. 19, No. 1, February 2019. josotl.indiana.edu 
- Mainstreaming all incoming UWL students into ENG 110;

- Using multiple measures placement (MMP);

- Creating a co-requisite support course (ENG 100).

\section{Mainstreaming}

The decision to mainstream all incoming UWL students into ENG 110 was based on discussions about the ethical implications of maintaining a basic FYW course, our analysis of the survey data, and our experiences in teaching the two pilot co-requisite sections of UWL 100. In short, we determined that with the additional support of a co-requisite course (more about that below), all UWL students should be able to succeed in ENG 110. The decision to mainstream all UWL students responds to calls from both the fields of RFY and FYW to remove, when possible, institutional barriers to students success, and to eliminate the bottlenecking of core course requirements that prevent students from making progress towards degree (Arney, Canada, Dale 2018). In mainstreaming all students into a credit-bearing FYW class, we have eliminated the issue of forcing students to spend time and money on a course that not only delays time to graduation, but also requires students to pay for a class that bears no credits.

\section{Multiple Measures Placement}

Our decision to mainstream all students into ENG 110 and to then conduct MMP for students within certain score ranges means that all students who would have previously placed into ENG 050 can confidently assume that they'll be earning ENG 110 credit during their first semester at UWL. In addition to the assurance that they'll be in a credit-bearing FYW course, these students will also have the same flexibility in scheduling ENG 110 that other students have always had. Moreover, because these students will not be segregated into ENG 050 classes, all instructors will have the opportunity to work with this population of students and the students will have access to a wide variety of sections of ENG 110 with diverse pedagogical practices and approaches to teaching FYW.

Our current system for placement uses student ACT or EPT scores for placement. All students admitted to UWL must have both sets of scores and our practice has been to use the higher of the two scores for placement. Our current cutoff scores for placement into ENG 110 is an ACT English sub-score $<19$ or an EPT score of 355 (on a scale of 800 possible points). As noted earlier, students scoring less than a 19 on the ACT and 355 on the EPT are automatically required to take ENG 050.

The revised placement system will require students who are in the cuspy area of both placement tests to undergo MMP. We're defining the cusp as an ACT English sub-score of 18-20 and an EPT score of 330-350. The chart below will be used by the Offices of the Registrar and Admissions to clarify and identify which students need additional placement measures.

Table 2: Placement Matrix

\begin{tabular}{|l|l|l|l|}
\hline & EPT Score $\leq 329$ & $\begin{array}{l}\text { EPT Score 330 - } \\
354\end{array}$ & $\begin{array}{l}\text { EPT Score } \\
\geq 355\end{array}$ \\
\hline ACT English 0 - 17 & $\begin{array}{l}\text { ENG 100 and ENG 110 } \\
\text { concurrent enrollment }\end{array}$ & MMP & ENG 110 \\
\hline
\end{tabular}

Journal of the Scholarship of Teaching and Learning, Vol. 19, No. 1, February 2019. josotl.indiana.edu 


\begin{tabular}{|l|l|l|l|} 
ACT English 18 - 20 & MMP & MMP & ENG 110 \\
\hline ACT English 21 - 36 & ENG 110 & ENG 110 & ENG 110 \\
\hline
\end{tabular}

There are a myriad of reasons why students score in this range and MMP allows us to better determine if students with these scores actually require additional support or not. The MMP process requires these students to complete a brief writing assignment--including a short description of the ways in which they might revise this assignment if they were asked to and a brief survey on their writing habits and experiences. The design of our MMP tool is based on the same survey we used in the pilot sections of UWL 100. Students complete this additional placement process online through a survey and have several days to complete the task. Then, we review student work looking at how each student's response demonstrates their ability to work through and follow a prompt, to synthesize sources and ideas at a beginning level, and to reflect on their writing choices.

Students who score ACT $>18$ or EPT $>330$ will automatically be placed into ENG 110 and ENG 100 without MMP. However, in addition to requiring a co-requisite course (for a total of six credits in English), we have also worked with our offices of admissions and the registrar to guarantee that students with these placement scores are provided with a schedule that does not require them to be in other writing-intensive general education courses (e.g. history) and that students take both ENG 110 and ENG 100 during the fall semester of their first year. Decisions like this further align the goals of FYW with the goals of RFY in terms of retention for first-year students (AACSU 2016).

Interestingly, our MMP tool also highlights additional important intersections between FYW and RFY. The MMP tool not only asks students to self-assess their writing habits, but in the writing component of the MMP, students are also asked to think about their writing in the context of "habits of mind," which include "curiosity, openness, engagement, creativity, persistence, responsibility, and metacognition" (Council 2011). These habits of mind and our revision of our FYW program echo the goals of the RFY program and, in particular, the question guiding the RFY work taking place at UWL, "What can we do as a university to better support the success of ALL of our students?" UWL adopted two main RFY pathways towards assuring student success, namely: "belonging in college and [. . .] growth mindset" (Arney, Canada, Dale 2018). In the context of our project, this means, at the institutional level, creating an easy path to credit-bearing courses and, at the course level, asking students to reflect on how their habits of mind affect their potential for success in the FYW classroom. The adoption of Carol Dweck's work on growth mindset in particular has affected how we designed the MMP and influenced our decision to work with habits of mind as a framework for assessing student preparedness for FYW. We will explore these connections further when we discuss ENG 100, the co-requisite support course, below.

\section{Corequisite Support Course--ENG 100}

While we are certainly not alone in our creation of a co-requisite support course as part of RFY (Arney, Canada, Dale 2018), this is a new move at UWL. This new course is based on the one-credit model developed in UWL 100 that was supported by the RFY initiative at UWL. While ENG 050 was somewhat stigmatized and resented by students because it was pass/fail and non-credit-bearing, the course offered crucial support for many students, and we wanted to retain the best of what the course offered, but to expand that work beyond the limitations of a one-credit class (e.g., not enough time to explore topics in depth or to provide students with enough one-on-one support). Therefore, we've designed ENG 100 with the following features:

Journal of the Scholarship of Teaching and Learning, Vol. 19, No. 1, February 2019. josotl.indiana.edu 
- credit bearing (three credits)

- graded

- portfolio-based

- embedded peer tutors (carryover from ENG 050)

- emphasis on low-stakes writing (carryover from ENG 050).

This course will provide students with additional opportunities to reflect on their writing habits; to more actively participate in activities that will prompt the habits of mind crucial to their development as writers; to develop a growth mindset about writing; and to receive additional practice in writing to hone their skills as writers and thinkers at the college level. These course goals align with the NCTE research policy brief, "FYW, What Good Does it Do?" (2013) acknowledgement that "High school and college students alike are empowered as agents responsible for their own learning when they are given the time and space to develop their meta-awareness as writers, and are explicitly taught how to do so (p. 2)." ENG 100 will provide students with space, time, and instruction that will directly reinforce both best practices in FYW instruction and the main goals of the RFY project at UWL.

One last measure of support built into ENG 100 is that while students can make their own choices about which section of ENG 110 they would like to take, they are not allowed to drop ENG 100, and if they drop their ENG 110, the registration system will automatically re-enroll them into ENG 110. This mechanism assures that students take the two courses during the same semester so that the skills students learn in ENG 100 can be directly applied to the work they're doing in ENG 110.

While this course will not replicate the work that takes place in ENG 110, it will provide support for the work students are doing in that course. Instructors teaching ENG 100 will be required to have a background in and/or prior experience in teaching developmental writing at the college level. ENG 100 instructors will work from a common syllabus which will facilitate communication about the purpose(s) and content of ENG 100 to ENG 110 instructors. Our hope is that this level of transparency about ENG 100 will encourage ENG 110 instructors to make connections between the two courses, to participate in conversations about how we can better support all of our student writers, and to create multiple points of intervention that ensure student success during their first year at UWL.

Each ENG 100 class will also have embedded tutors who will provide additional one-on-one instruction for students and serve as peer mentors. ENG 050 has always used embedded peer tutors who were trained through and also worked in the university's Writing Center; therefore, we felt ENG 100 should preserve this feature, as the peer tutors provide several important services or functions. They come to class every day, having done at least the readings the students have done, so they can answer informal questions as well as lead more structured group discussions. They also work with students through invention, drafting, and revision activities in class, either individually or in small groups, and they facilitate peer review. They offer their own perspectives on writing, connecting what the professor presents to experiences and courses closer in time and perspective to the students. Additionally, they can provide another source of information and assessment for the professor, alerting her to challenges or problems or successes that students might be less willing to share with her, contributing to assessment of students' progress, and collaborating to present information or design activities. Our use of embedded peer tutors then also responds to one of the main goals for RFY on our campus; namely, to provide students with a sense of belonging. For students who are taking ENG 100 they will not only experience the educational advantages that a support course can provide, but they will also benefit from one-on-one peer interaction that can help to demystify the first-year experience and create additional points of intervention for students who might feel lonely or isolated on our campus.

Journal of the Scholarship of Teaching and Learning, Vol. 19, No. 1, February 2019. josotl.indiana.edu 
The last, although not insignificant, issue that we will need to address is how we frame ENG 100 for students who are required to take the course. Our goal of eliminating the stigma of a required remedial course in writing has been addressed from our perspective; however, from a student perspective--a perspective that has no knowledge about our prior system for working with developmental writers--they're still required to take an additional writing course. To address these concerns, we've created additional information, context, and resources for students on our departmental website and we will have an additional faculty member available during our summer registration to ensure that students (and potentially parents) have access to information about MMP and ENG 100 in a variety of formats.

\section{Conclusion}

While the impetus for the curricular changes we've made to our FYW program has been student success, the effects of these changes will also be felt among the instructors in our program as well. Because department approval is required for programmatic changes, we found ourselves frequently describing the problems associated with remedial English classes, the research supporting the revisions we were suggesting for our program, and the results of our SoTL project with our colleagues. The overall effect of sharing our research with our department has been a highlighting of the importance of the work of FYW on our campus and a confirmation that scholarship in this field is not just theoretical, it's also applied and, therefore, lived. In other words, our work was not in the abstract; rather, we were making changes that would affect our students on our campus.

As we write this article, we're on the precipice of major changes in our FYW program--summer 2018 will be our first opportunity to officially engage in MMP, and we will be offering our first sections of ENG 100 in the fall of 2018. While our work will affect only a small percentage of students at UWL, the principles guiding this work will invariably have an effect on our FYW classes as well. For example, while ENG 110 instructors will not know which students are also required to take ENG 100, we will be sharing the syllabus for ENG 100 with all of the FYW instructors in our department so that instructors can build off the instruction in ENG 100 as they design their sections of ENG 110. In the past, work with students who placed into ENG 050 was largely conducted in private; only three or four instructors out of a department of approximately 35 were aware of the structure, content, and pedagogical approaches being used in the course. Through mainstreaming, improved placement practices, and the development of ENG 100 we're hoping those days are now behind us.

Additionally, because we were required to seek out campus-wide approval for the changes we were proposing (from our general education program to our office of the registrar and everywhere in between), we have had ample opportunities to frame our work to our campus community as an example of how social justice can be enacted through curricular revision. It's difficult to overestimate the effects of this kind of conversation on our campus. Our work serves as evidence of the importance of FYW to FYE (and vice versa), the influence of the RFY initiative on campus curricular reform, and the effects that conscientious SoTL work can have on our teaching and learning communities.

\section{References}

American Association of State Colleges and Universities. (2016). Re-Imagining the First Year of College: About RFY. Retrieved from http://www.aascu.org/RFY/

Arney, Jo, Canada, Mark, Dale, Tim. (2018). Re-Imagining the first year on campus: A closer look at Indiana University Kokomo and the University of Wisconsin La Crosse. Change Magazine

Journal of the Scholarship of Teaching and Learning, Vol. 19, No. 1, February 2019. josotl.indiana.edu 
Broad, Bob. (2003). What We Really Value: Beyond Rubrics in Teaching and Assessing Writing. Louisville, CO: University Press of Colorado.

Brunk-Chavez, Beth and Frederickson, Elaine (2008). Predicting success: Increasing retention and pass rates in college composition. Writing Program Administration, 32 (1), 76-96. Retrieved from http://www.wpacouncil.org/archives/32n1/32n1brunk-chavezfredericksen.pdf

Complete College America. Corequisite Remediation: Spanning the Completion Divide. Retrieved from http://completecollege.org/spanningthedivide/

Council of Writing Program Administrators, National Council of Teachers of English, National Writing Project. (2011). Framework for Success in Postsecondary Writing. Retrieved from http://wpacouncil.org/framework

Dweck, Carol S. (2006). Mindset: The New Psychology of Success. New York, New York: Random House.

Garrett, Nathan, Bridgewater, Matthew, and Feinstein Bruce (2017). How student performance in first-year composition predicts retention and overall student success. In Ruecker, Todd, Shepherd, Dawn, Estrem, Heidi, and Brunk-Chavez, Beth (Eds)., Retention, Persistence, and Writing Programs. Louisville, CO: University Press of Colorado.

Hassel, Holly and Baird Giordano, Joanne (2011). First-year composition placement at openadmission, two-year campuses: Changing campus culture, institutional practice, and student success. Open Words: Access and English Studies, 5 (2), 29-59.

Haswell, Richard H. (2004). Post-secondary entry writing placement: A brief synopsis of research. $W A C$ Clearinghouse. Retrieved from https://wac.colostate.edu/docs/comppile/pd/writingplacementresearch.htm

Huot, Brian. (2002). (Re) Articulating Writing Assessment. Louisville, CO: University Press of Colorado.

National Council of Teachers of English (2013). First-Year Writing: What Good Does it Do? Retrieved from http://www.ncte.org/library/NCTEFiles/Resources/Journals/CC/0232nov2013/CC0232Policy.pdf

National Student Clearinghouse Research Center. (2014). Completing College: A National View of Student Attainment Rates (8). Retrieved from https://nscresearchcenter.org/signaturereport8/

Powell, Pegeen Reichert (2009). Retention and writing instruction: Implications for access and pedagogy. College Composition and Communication, 60 (4), 664-682. Retrieved from http://www.jstor.org/stable/40593424

Strayhorn, Terrell, Hurtado, Sylvia, Harris, Quartez. (2012). College Students' Sense of Belonging: A Key to Success for All Students. New York, New York: Routledge.

US News \& World Report. (2018). Top Public Schools, Regional Universities Midwest. Retrieved from https://www.usnews.com/best-colleges/rankings/regional-universities-midwest/top-public

Journal of the Scholarship of Teaching and Learning, Vol. 19, No. 1, February 2019.

josotl.indiana.edu 